\title{
Study on the Factors of Online Shopping Intention for Fresh Agricultural Products Based on UTAUT2
}

\author{
Liping $\mathrm{An}^{1}$, Yaqi Han ${ }^{2}$, Lingyun Tong ${ }^{2 *}$ \\ ${ }^{1}$ School of Business, Nankai University, China \\ ${ }^{2}$ School of Economics and Management, Hebei University of Technology, China \\ *tonglingyun2008@126.com
}

Keywords: fresh agricultural products; UTAUT2; online shopping intention

\begin{abstract}
To analyze the factors influencing online shopping intention for fresh agricultural products, this paper constructs a research model based on UTAUT2. Data obtained from questionnaires are processed using structural equation model. The results show that performance expectancy, effort expectancy, hedonic motivation, facilitating conditions have positive impacts on the online shopping intention for fresh agricultural products, gender has a significant influence on the measuring model, while neither experience nor personal innovativeness has influence on the measuring model.
\end{abstract}

\section{Introduction}

With the rise of the internet economy, e-commerce has been developed rapidly. Most e-commerce focuses on clothing, electronic products, daily necessities, etc. while e-commerce of agricultural products is almost stagnated. The main reasons include the limitation of agricultural products' seasons and geographical restrictions, consumers' role could not be ignored.

Based on a review of the extant literature, Venkatesh et al. developed UTAUT as a comprehensive synthesis of prior technology acceptance research [1]. UTAUT has four key constructs (i.e., performance expectancy, effort expectancy, social influence, and facilitating conditions) that influence behavioral intention to use a technology and/or technology use.

Venkatesh et al. extended UTAUT to study acceptance and use of technology in a consumer context. Three constructs (i.e., hedonic motivation, price value, and habit) were incorporated into UTAUT. Individual differences-namely, age, gender, and experience-were hypothesized to moderate the effects of these constructs on behavioral intention and technology use [2]. That is UTAUT2.

This paper analyzes the factors of online shopping intention for fresh agricultural products based on the extended unified theory of acceptance and use of technology (UTAUT2). From which we can understand the behavior of consumers online shopping fresh agricultural products. It can be used to make some suggestions for e-commerce development strategy of fresh agricultural products.

\section{Model Formulation and Hypothesis Development}

Online shopping fresh agricultural products is in initial step in our country. The proportion of consumers online shopping fresh agricultural products is relatively lower. Few people are accustomed to online shopping fresh agricultural products. Thus, in this paper, online shopping intention is the final construct rather than online shopping behavior, the construct habit is dropped. In UTAUT2, price value was defined as consumers' cognitive tradeoff between the perceived benefits of the applications and the monetary cost for using them. In the e-commerce environment, consumers think that no any additional costs should be paid for online shopping [3, 4], so the construct price value is dropped, too. Because of the characteristics of the online shopping environment and fresh agricultural products, two constructs (i.e., perceived risk, personal innovativeness) are incorporated into the research model.

There are three moderators in UTAUT2, in this paper, age is dropped because of the consumers' 
age is relatively concentrated. Personal innovativeness is not only a construct, but also a moderator. Figure 1 presents the research model.

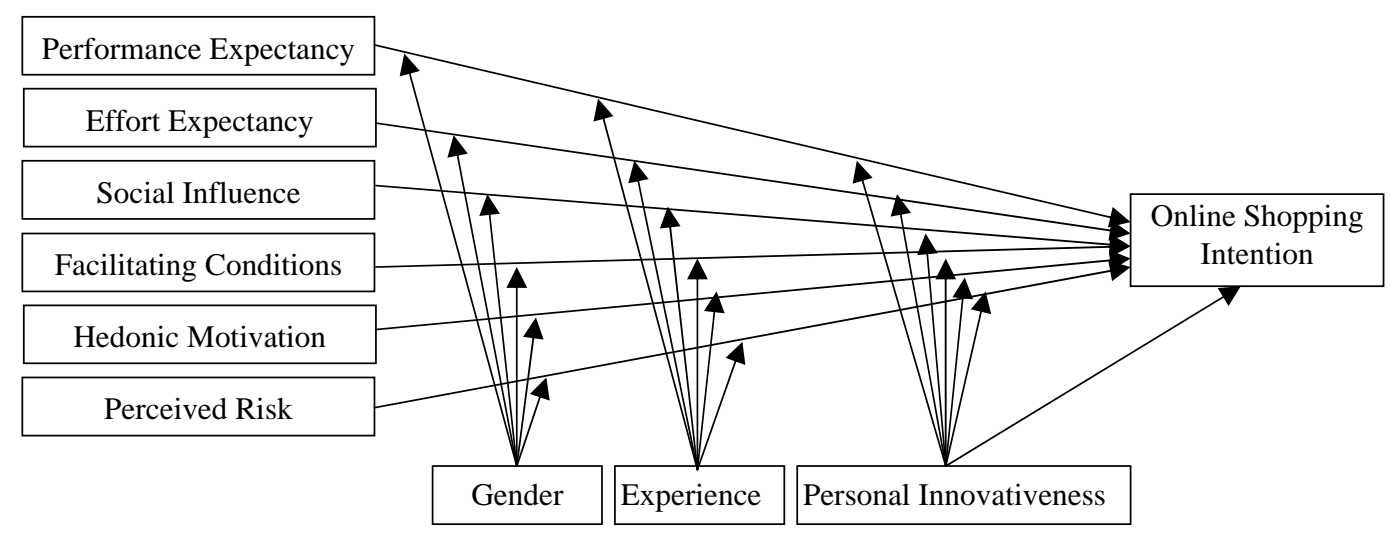

Figure 1. Research Model

The related hypotheses are as follows:

Hypotheses related to reserved constructs:

H1: Performance expectancy of consumers is positive related to online shopping intention;

H2: Effort expectancy of consumers is positive related to online shopping intention;

H3: Social influence is positive related to online shopping intention;

H4: Facilitating conditions is positive related to online shopping intention;

H5: Hedonic motivation is positive related to online shopping intention.

Hypotheses related to added constructs:

Perceived risk is more and more important to explain the consumer's purchase behavior. Pavlou, Forsythe thought perceived risk was negatively related to consumer intentions [5, 6]. Yang et al. studied on mobile payment initial adoption, they found the same rule [7]. Thus,

H6: Perceived risk of consumers is negatively related to online shopping intentions.

Agarwal et al. studied personal innovativeness in the domain of information technology [8], which was hypothesized to exhibit moderating effects on the antecedents as well as the consequences of individual perceptions about a new information technology. Teng found that internet innovativeness had a significant positive effect on internet shopping [9]. Thus,

H7: Personal innovativeness of consumers is positive related to online shopping intention.

Hypotheses related to moderators:

H8: Gender has a significant moderating effect on the measurement model;

H9: Experience has a significant moderating effect on the measurement model;

H10: Personal Innovativeness has a significant moderating effect on the measurement model.

\section{Empirical Verification}

3.1 Measurement and Data Collection. On the basis of past research, combined with the characteristics of online shopping fresh agricultural products, the scales of this paper is designed. All items are measured using a five-point Likert scale, with the anchors being "strongly disagree" and "strongly agree". The questionnaire is divided into two parts, one is the personal information of the respondents, such as gender, age, occupation, etc; the other is the measurement scale. The questionnaire is pilot tested among a group of older, employed students. According to the feedback, some items are modified.

As a result of the formal investigation, 387 questionnaires in 435 ones are valid, the effective recovery rate is $\mathbf{8 8 . 9 \%}$. The sample information is pretty much the same as that in white paper on e-commerce of Agricultural products, and agree with the desired results. But only $19.3 \%$ of respondents ever online shopped fresh agricultural products. That means the acceptance ratio of online shopping fresh agricultural products is low, there is still much room for development.

3.2 Reliability and Validity Assessing. Data obtained from the questionnaires are processed in 
SPSS. Cronbach's $\alpha$ coefficient is used to assess scale's internal consistency reliability. If Cronbach's $\alpha$ coefficient is greater than 0.7 , the result is reliable. Table 1 shows that this research has high reliability level.

Table 1. Reliability analysis of the formal questionnaire

\begin{tabular}{cccc}
\hline construct & code & items & Cronbach's $\alpha$ \\
\hline Performance Expectancy & PE & 4 & 0.807 \\
Effort Expectancy & EE & 3 & 0.817 \\
Social Influence & SI & 3 & 0.828 \\
Facilitating Conditions & FC & 4 & 0.783 \\
Hedonic Motivation & HM & 4 & 0.848 \\
Perceived Risk & PR & 4 & 0.823 \\
Personal Innovativeness & PI & 4 & 0.829 \\
Online Shopping Intention & OSI & 3 & 0.843 \\
\hline
\end{tabular}

Validity could be divided into convergent validity and discriminant validity. Confirmatory factor analysis ( CFA) is used to assess the validity of the questionnaire further in AMOS. The result shows that all latent variables are greater than 0.5 , all combined validity is greater than 0.8 , all average variance extracted(AVE) are greater than 0.5 . That is, the measurement model has good convergent validity. As to discriminant validity, comparing two constructs' AVE and the square of correlation coefficients $\left(\mathrm{R}^{2}\right)$, if the former is greater than the latter, that means the two constructs have good discriminant validity. The result is shown in table 2, it means the measurement model has good discriminant validity.

Table 2. Square of correlations and AVEs

\begin{tabular}{ccccccccc}
\hline construct & PE & EE & SI & HM & PI & PR & FC & OSI \\
\hline PE & 0.516 & & & & & & & \\
EE & 0.253 & 0.611 & & & & & & \\
SI & 0.188 & 0.221 & 0.546 & & & & & \\
HM & 0.328 & 0.141 & 0.274 & 0.589 & & & & \\
PI & 0.199 & 0.161 & 0.181 & 0.247 & 0.538 & & & \\
PR & 0.002 & 0.012 & 0.029 & 0.030 & 0.002 & 0.628 & & \\
FC & 0.187 & 0.222 & 0.299 & 0.128 & 0.208 & 0.192 & 0.550 & \\
OSI & 0.364 & 0.315 & 0.381 & 0.394 & 0.343 & 0.016 & 0.531 & 0.641 \\
Note: Diagonal elements are AVEs and off-diagonal elements are square of correlations
\end{tabular}

3.3 Hypotheses Test. In this paper, model-fitting analysis is conducted in AMOS, each fitting index conforms to expert's recommendation. The overall fit of the structural model is better. It means this paper's structure model fits well with samples, it can be used to test hypotheses. The test result is shown in table 3.

\begin{tabular}{ccccccc}
\multicolumn{7}{c}{ Table 3. Test of hypotheses } \\
\hline path & Estimate & S.E. & C.R. & P & hypothesis & Supported? \\
\hline $\mathrm{PE} \rightarrow$ OSI & 0.126 & 0.047 & 2.663 & $* *$ & H1 & YES \\
$\mathrm{HM} \rightarrow$ OSI & 0.183 & 0.052 & 3.528 & $* * *$ & H5 & YES \\
$\mathrm{FC} \rightarrow$ OSI & 0.399 & 0.082 & 4.883 & $* * *$ & H4 & YES \\
$\mathrm{EE} \rightarrow$ OSI & 0.178 & 0.056 & 3.176 & $* *$ & $\mathrm{H} 2$ & YES \\
$\mathrm{SI} \rightarrow$ OSI & 0.102 & 0.063 & 1.619 & 0.105 & $\mathrm{H} 3$ & NO \\
$\mathrm{PR} \rightarrow$ OSI & -0.036 & 0.063 & -0.570 & 0.568 & H6 & NO \\
$\mathrm{PI} \rightarrow$ OSI & 0.230 & 0.054 & 4.264 & $* * *$ & H7 & YES \\
\hline
\end{tabular}

Note: ${ }^{*} \mathrm{p}<0.05 ;{ }^{* *} \mathrm{p}<0.01 ;{ }^{* * *} \mathrm{p}<0.001$; all other correlations are insignificant.

Regardless of the moderators, table 3 shows that social influence and perceived risk have no significant effect on online shopping intention, yet others have significant effect at the $95 \%$ confidence level.

3.4 Test of Moderators. In this paper, moderators are tested in AMOS, this is a kind of SEM multi-group analysis.

Gender is one of the three moderators. In a total of 387 respondents, there are 181 males, 206 females. The fitting index of each group is calculated separately, the result is shown in table 4 . 
Table 4. Gender fitting index

\begin{tabular}{cccccccc}
\hline & CMIN & DF & CMIN/DF & IFI & TLI & CFI & RMSEA \\
\hline Male & 772.140 & 440 & 1.755 & 0.886 & 0.879 & 0.884 & 0.065 \\
Female & 807.984 & 440 & 1.836 & 0.899 & 0.884 & 0.898 & 0.064 \\
\hline
\end{tabular}

Table 4 shows that female group fits better. IFI, TLI and CFI are all close to 0.9. The analysis data of gender can basically reach the fit state with the theoretical model, so, gender is suitable for multi-group analysis.

The two groups' regression coefficients are restricted to be corresponding equal. Then we use chi-square values to test for significant level. The result is shown in table 5.

Table 5. Moderated by gender

\begin{tabular}{ccccccc}
\hline DF & CMIN & P & NFI & IFI & RFI & TLI \\
\hline 23 & 47.329 & 0.002 & 0.006 & 0.007 & 0.001 & 0.001 \\
\hline
\end{tabular}

Table 5 shows that gender can moderate the effect of all constructs on online shopping intention for fresh agricultural products.

Using the similar procedure, we can see neither personal innovativeness nor experience can moderate the effect of any construct on online shopping intention.

\section{Conclusions}

This paper constructs a research model to analyze the factors influencing online shopping intention for fresh agricultural products. The results show that performance expectancy, effort expectancy, facilitating conditions, hedonic motivation and personal innovativeness are related to online shopping intention, gender can moderate the effect of constructs on online shopping intention.

\section{References}

[1] V. Venkatesh, M.G. Morris, G.B. Davis, et al. 2003. User acceptance of information technology: toward a unified view, MIS Quarterly, 27(3): 425-478.

[2] V. Venkatesh, J.Y.L. Thong, X. Xu. 2012. Consumer acceptance and use of information technology: extending the unified theory of acceptance and use of technology, MIS Quarterly, 36 (1): 157-178.

[3] C.S. Yu. 2012. Factors affecting individuals to adopt mobile banking:empirical evidence from the UTAUT model, Journal of Electronic Commerce Research, 13(2): 104-121.

[4] F.J. Pascual-Miguel, et al. 2015. Influences of gender and product type on online purchasing, Journal of Business Research, 68(7): 1550-1556.

[5] P.A. Pavlou. 2003. Consumer acceptance of electronic commerce: integrating trust and risk with the technology acceptance model, International Journal of Electronic Commerce, 7(3):101-134.

[6] S.M. Forsythe, B. Shi. 2003. Consumer patronage and risk perceptions in internet shopping, Journal of Business Research, 56(11): 867-875.

[7] S.Q. Yang, Y.B. Lu, Y.Z. Cao. 2012. An empirical study on mobile payment initial adoption, Chinese Journal of Management, 9(9): 1365-1372

[8] R. Agarwal, J. Prasad. 1998. A conceptual and operational definition of personal innovativeness in the domain of information technology, Information Systems Research, 9(2): 204-215.

[9] H.B. Teng. 2013. Consumer innovativeness and Internet shopping, Science Technology and Industry, 13(10): 85-91 